\title{
Everyday Racism as Predictor of Political Racism in Flemish Belgium
}

\author{
Jaak Billiet* and Hans de Witte \\ Katholieke Universiteit Leuven
}

Two aspects of research on racism in Flanders (Belgium) are discussed in this article based on results from large-scale surveys between 1991 and 2003. The first relates to the (negative) attitudes of the majority toward foreigners (everyday racism). The second relates to the vote for an extreme right-wing political party that emphasizes anti-immigrant viewpoints in its political program and propaganda (political racism). Our main research question is how both forms of racism are related. First, theories to explain political racism are reviewed. Some theories suggest an extreme right-wing vote to be motivated by a content-related agreement with (part of) the program of these parties (e.g., racism, nationalism, or authoritarianism). Other theories suggest that this vote represents an antipolitical protest vote. From these theories, hypotheses are derived regarding the background characteristics and attitudes that are associated with an extreme right-wing vote (e.g., the Vlaams Blok). These hypotheses are tested using data from election research in 1991, 1999, and 2003. The results suggest that the vote for the party Vlaams Blok is a rational vote. Of all theories, the theory suggesting that everyday racism plays a prominent role received most support. Everyday racism thus motivates political racism in the Flemish part of Belgium.

The topic of racism has been the focus of an extensive amount of research in the Flemish part of Belgium during the last few decades. Two aspects of this topic have been studied most intensively: the attitudes of the majority toward foreigners or immigrants and extreme right-wing voting behavior. In this article, both research lines will be combined.

* Correspondence concerning this article should be addressed to Jaak Billiet, Department of Sociology, Katholieke Universiteit Leuven, Parkstraat 45, Leuven 3000, Belgium [e-mail: Jaak.billliet@soc.kuleuven.be].

The data used in this article are compiled by the ISPO as part of the AGORA programme, supervised by the Belgian Science Policy. 
In previous research in Belgium, a Likert-type scale was developed to measure negative attitudes toward migrants (Billiet \& De Witte, 1995). Central to this negative attitude is the idea that foreigners' cultural habits are too deviant from those of the Belgians, for example, "Foreigners are a threat to our culture and habits," and that they represent economic competition, for example, "Migrant workers threaten the employment of Belgians." This attitude can be understood as a form of everyday racism (for an overview, see De Witte, 1999). In his extensive overview of Belgian opinion polls, De Baets concluded that the level of everyday racism has not been rising over the recent decades and has possibly even decreased since the decolonization of the Belgian Congo in 1960 (De Baets, 1994).

Political racism refers to the vote for a political party that strongly emphasizes anti-immigrant viewpoints in its political program and propaganda (see e.g., De Witte and Klandermans, 2000). In the Flemish context, the extreme right-wing party Vlaams Blok is commonly referred to as a political racist party by experts and the media. In the 1991 General Elections for the Federal Parliament, the Vlaams Blok obtained $9.3 \%$ of the Flemish vote. This number rose to $17.1 \%$ in the 2003 General Elections and $19 \%$ in the 2007 General Elections. ${ }^{1}$ The party even obtained $22.8 \%$ of the Flemish vote in the 2004 elections for the Flemish Parliament and became the largest political party in Flanders (Fraeys, 2004). The Vlaams Blok did not emerge from a vacuum but was able to build on an existing network of individuals who were active on the radical fringe of the Flemish Movement. The militants needed to engage in party activities and were thus available, and they had already been active in the political struggle. This facilitated the development of a coherent party. The majority of Vlaams Blok representatives elected in 1991 had previously been active in organizations of ideologically trained activists who made it possible to extend the party structures further. Another factor facilitating this development was the highly organized and tightly centrally led character of the Vlaams Blok as a party (Spruyt, 1995).

A core issue in the ideology of the Vlaams Blok is the preference for a monocultural and monoracial national state, in which "nation" is conceived as a "biologically defined ethnic community" (De Witte \& Klandermans, 2000). Partly as a consequence, the party was convicted of racism by a Belgian court in 2004. Over the past decades, and, in particular, since the parliamentary elections of November 24, 1991, the Vlaams Blok electorate has been the subject of thorough electoral research (e.g., Billiet and De Witte, 1995, 2001) and Swyngedouw and Billiet (2002). These studies were because of the large Flemish samples in the election

\footnotetext{
${ }^{1}$ The percentages are based on the number of voters that went to the polls (blank and invalid included). Suffrage in Belgium is based on the "one man, one vote" principle. Every Belgian national, male or female, who has reached the age of 18 has the duty to cast a vote. Belgium is characterized by a multiparty electoral system with proportional representation.
} 
surveys of the Institute of Social and Political Opinion Research (ISPO) in 1991, 1995,1999 , and $2003 .^{2}$

In this article, we will discuss the relationship between everyday and political racism by focusing on the attitudinal determinants of a vote for the extreme rightwing party Vlaams Blok. Our main research question is whether both forms of racism are related: does everyday racism constitute an important determinant for political racism? Stated otherwise, do people who hold racist attitudes vote for a party that advocates racism in its political platform and propaganda? The following overview of the literature on extreme right-wing voting behavior suggests that the answer to this question is less than obvious because racism appears to be just one of many possible motives discussed in these theories. Data of postelectoral voter surveys carried out by ISPO between 1991 and 2003 will be used to test hypotheses related to the background characteristics of the Vlaams Blok voters and to the typical social attitudes of this electorate. Because we analyze data for a period of over 10 years, we can also analyze whether the determinants of the Vlaams Blok vote changed over time.

\section{Theoretical Explanations of Extreme Right-Wing Voting}

Two broad and competing hypotheses are presented in the literature regarding the reasons for voting for an extreme right-wing party (e.g., Van der Brug, Fennema, $\&$ Tillie, 2000). These may be termed the rational vote versus the protest vote.

\section{A Substantive, Rational Vote}

In this view, the choice of an extreme right-wing party expresses a contentrelated agreement with (an aspect of) the program or political platform of this party. This view is in agreement with the rational choice model of voting behavior (Himmelweit, Humphreys, Jaeger, \& Katz, 1981), in which issue voting and ideological reasons are emphasized as determinants of voting behavior. These content-related reasons can be derived from various theories. For a more detailed discussion, see Lubbers and Scheepers (2000) and Lubbers (2001).

Negative attitudes toward foreigners (everyday racism) play a crucial role in the theory of threatened economic interests (De Witte, 1999; Lubbers, 2001) because the economic threat attributed to foreigners is emphasized. The theory of threatened economic interests states that voters vote for the political party that claims to defend their economic interests. Voters who feel threatened in economic

${ }^{2}$ The election surveys of 1991, 1995, 1999, and 2003 were carried out by the Institute of Social and Political Opinion Research (ISPO). The research group consisted of J. Billiet, M. Swyngedouw, A. Carton, and R. Beerten. The election survey was financed by the former Federal Offices for Cultural and Technical Assistance (DWTC). 
terms by immigrants develop, in this view, a preference for political parties that wish to reduce the presence of immigrants in society. Blue-collar workers and low-skilled individuals, in particular, hold positions in economically unstable sectors. This results in heightened feelings of job insecurity among these categories (Näswall \& De Witte, 2003). As a consequence, they are more likely to vote for an extreme right-wing party.

The theory of symbolic interests (e.g., Lubbers \& Scheepers, 2000) stresses the effects of disintegration caused by processes of modernization and social exclusion. This theory assumes that disintegrated individuals are more likely to be receptive to nationalism because nationalism constitutes a symbolic substitute for social integration by offering them new group bounds and an identity. According to this theory, alienated individuals vote for an extreme right-wing party because these parties proclaim nationalism. In this view, nonchurchgoers, young people, individuals not associated with the traditional "pillar" organizations, and voters who do not actively participate in organizational life will be more likely to vote for an extreme right-wing party because they are less socially integrated.

The theory of psychological compensation highlights the importance of authoritarianism (Adorno, Frenkel-Brunswik, Levinson, \& Sanford, 1950). At present, authoritarianism is conceived as an attitude dimension with three basic components (Altemeyer, 1998): conventionalism (rigid conformism to conventional norms and strict moral codes), authoritarian submission (uncritical and full submission to ingroup authorities), and authoritarian aggression (fierce rejection and punishment of violators of conventional norms). According to this theory, voters feel attracted to extreme right-wing parties because of the authoritarian concepts embodied by these parties (Adorno et al., 1950). Blue-collar workers and low-skilled individuals score higher on authoritarianism (Meloen, 1994) and will thus be attracted by extreme right-wing parties.

\section{An Antipolitical Protest Vote}

The theory of protest voting opposes the rational vote view. In this theory, the vote for an extreme right-wing party is motivated by a rejection of the political system and of politicians (e.g., Van der Brug et al., 2000). The program of such a party thus becomes irrelevant because the choice of an extreme right-wing party is solely the expression of apolitical protest. The hypothesis of the antipolitical protest vote suggests that attitudes such as political dissatisfaction, powerlessness, and distrust are the most important determinants of an extreme right-wing vote. Social categories that are characterized by these attitudes are those with a higher probability of voting for such parties. Depending on the attitude selected, this relates to blue-collar workers, low-skilled individuals, young people, nonchurchgoers, individuals not associated with the traditional pillar organizations, and voters who do not actively participate in organizational life. Research shows that these social categories indeed score more highly in terms of political 
dissatisfaction, powerlessness, anomy, and mistrust (see e.g., Swyngedouw \& Billiet, 2002).

\section{Hypotheses}

A first set of hypotheses relates to background characteristics that are supposed to be associated with the vote for an extreme right-wing party (the Vlaams Blok). A higher probability of a Vlaams Blok vote is expected among blue-collar workers, low-skilled individuals, nonchurchgoers, young people, respondents not associated with the traditional pillar organizations, and voters who do not actively participate in organizational life. Note, however, that the confirmation of these hypotheses often corroborates more than one theory at the same time because several theories lead to the prediction of the same association with background characteristics. The higher probability to vote Vlaams Blok among blue-collar workers and low-skilled individuals, for instance, will corroborate no less than three theories: the theory of threatened economic interests, the theory of psychological compensation, and the theory of protest voting.

Our second set of hypotheses relates to the social attitudes associated with a vote for the Vlaams Blok. This set enables us to discriminate between the four theories as each theory suggests specific attitudes to lead to the vote for an extreme right-wing party. This second set also enables us to answer our core research question: the relationship between everyday and political racism. A negative attitude toward ethnic minorities will be evidence in favor of the theory of threatened economic interests, Flemish nationalism for the theory of symbolic interests, authoritarian attitudes for the theory of psychological compensation, and political inefficacy and distrust for the theory of protest voting.

\section{Method}

\section{Data}

This study uses the general election surveys of ISPO of 1991, 1999, and 2003. The 1995 data are not presented because the 1995 sample of respondents is mostly identical to the sample of 1991 and because only minor differences were observed (see Billiet \& De Witte, 2001). The face-to-face interviews of the 1991 and 1999 surveys were performed by trained interviewers of the ISPO interviewer network. The 1991 fieldwork started directly after the elections in December 1991 to March $1992(N=2,691$; response rate of $66 \%)$. The 1999 survey was carried out by the ISPO interviewer network between September 1999 and March $2000(N=2,178$; response rate also 66\%). The fieldwork related to the 2003 elections took place in January 2004 to March 2004 and was carried out by interviewers of a commercial bureau (significant), but controlled by a researcher of ISPO $(N=1,215$; response rate of $69 \%$ ). As expected, the Vlaams Blok is somewhat underrepresented in the 
data file. This is partly related to the underrepresentation of low-skilled individuals in the surveys. In order to correct this underrepresentation, weighted data are analyzed.

\section{Measurements}

The ISPO election surveys gathered information about the level of education (four levels), age (five categories), professional category (seven categories), religious involvement (five categories), membership in a health insurance fund, membership in a trade union, and active membership in voluntary associations. These variables were measured in exactly the same way in all surveys. Apart from Catholics or those who describe themselves as Christian, few respondents of other religions were present in the sample. In consequence, categories are divided according to the extent of religious involvement. We distinguish between marginal Catholics (who attend church only on special family occasions), irregular churchgoers (who also attend church on religious holidays), and those who attend church services with great regularity (regular churchgoers). Among the nonbelievers, a distinction is made between explicit free thinkers (nonreligious humanists) and people who claim to have no religious beliefs. Membership in a trade union or professional association and affiliation with a health insurance fund are included in order to measure the association with the traditional pillar organizations. Gender was added to the analysis for exploratory reasons and as a control variable.

In order to explain voting behavior, a range of attitude scales or social attitudes was included in all electoral surveys. The exact phrasing of all items has been published elsewhere (Billiet, Swyngedouw, Depickere, \& Meersseman, 2001). All scales were converted into 11-point scales, ranging from 0 (minimum) to 10 (maximum). The highest scores always indicate an agreement with the concept mentioned in the name of the scale. The sets of items were largely the same in the 1991 and 1999 surveys, but smaller sets with only the most relevant items were used in the survey of 2003. Relevant deviations in the scales are reported below.

To measure a negative attitude toward immigrants (or everyday racism) only four items that are identical across the three surveys are available. These items express feelings of being threatened by immigrants in the domains of culture, customs, and social security. A fourth item expresses distrust of immigrants. The internal consistency (Cronbach's $\alpha$ ) of these scales varies between .76 (1991), .81 (1999), and .83 (2003). Multigroup structural equation modeling shows that the reduced 4-item scale is factorially invariant in the three samples, indicating that the measurements are equivalent over time (Billiet, Goffé, \& Maddens, 2007).

In order to measure nationalism, five items were used that measure (sub)national identity and the support for Flemish autonomy. High scores indicate that the respondents are in favor of more autonomy for Flanders, support the division of social security, and regard themselves as more Flemish than Belgian. The scale thus refers to Flemish nationalism. The indicators are mixed because 
they measure aspects such as national identity, national awareness, and attitudes toward separatism. The reliability of this scale is fairly high $(\alpha=.80)$. Multigroup structural equation modeling shows that the latent variable was factorially invariant in the 1991 and 1999 samples, indicating that the measurements are equivalent. However, the 2003 scale is no longer measurement equivalent because two items were changed. As a consequence, a strict comparison between the 2003 and the previous surveys is impossible.

The authoritarian attitudes measured refer to obedience and respect for authorities, strong leadership, and aggression toward those who do not conform to norms. The scale contained six items in 1991 and had moderate measurement quality $\left(\alpha_{1991}=.75\right)$. In 1999 , an attempt to construct a new scale with a balanced set of items failed. Only five items, worded in the direction of authoritarianism, measured the concept $\left(\alpha_{1999}=.69\right)$. Due to changes in the item content, this scale is not completely comparable to the scale that was used in 1991. There is no comparable measurement of authoritarianism in the 2003 survey. However, one particular aspect of authoritarianism, severe repression against criminals, was included in both the 1999 and 2003 surveys. Four items, dealing with severe sanctioning of criminal behavior, measure the concept in a reliable way $\left(\alpha_{1999}=.81 ; \alpha_{2003}=.73\right)$. From a theoretical point of view, one can argue that this attitude forms part of the authoritarian aggression dimension of authoritarianism (Adorno et al., 1950). This is also corroborated empirically as the correlation between the scales of authoritarianism and repression against criminals was .64 in the 1999 survey.

We combined distrust in politics and political inefficacy into one general concept, measured with five identical items in both the 1999 and 2003 surveys. The items express distrust in elections, in political parties, and in politicians. The latter are perceived as persons who do not listen to ordinary people, who are not interested in the opinions of the citizens, and who promise much, but do nothing. The scale is highly internally consistent $\left(\alpha_{1999}=.85 ; \alpha_{2003}=.81\right)$. The scale that was used in 1991 had lower measurement quality $\left(\alpha_{1991}=.71\right)$ and was smaller in scope. It contained three items measuring political inefficacy only. This scale is not equivalent with the scales that are used in 1999 and 2003.

In all surveys, a question was asked regarding the vote of the respondent during the elections that were held before the survey took place. This actual voting behavior will be the dependent variable in all analyses.

Analysis

In order to estimate the effect of background variables on the probability of a vote for the Vlaams Blok, a logistic regression via the CATMOD procedure of SAS is used. In this multinomial logit analysis, the dependent variable is not the probability of a Vlaams Blok vote, but the probability ratio, Vlaams Blok/other parties. The analysis is performed in a two-step procedure. The social background variables are included in the models in the first step. In doing so, we obtain information 
Table 1. Net Effect of Background Characteristics on Voting for the Vlaams Blok in the Elections to the House of Representatives in Flanders in 1991, 1999, and 2003 Estimated Using a Logit Model ${ }^{\mathrm{a}}$

\begin{tabular}{|c|c|c|c|}
\hline $\begin{array}{l}\text { Background Variable } \\
\text { Grand Mean }\end{array}$ & $\begin{array}{c}\text { Vlaams } \\
\text { Blok'91 } \\
9.7(\text { Obs.\%) }\end{array}$ & $\begin{array}{c}\text { Vlaams } \\
\text { Blok'99 } \\
14.7(\text { Obs.\%) }\end{array}$ & $\begin{array}{c}\text { Vlaams } \\
\text { Blok'03 } \\
17.07 \text { (Obs.\%) }\end{array}$ \\
\hline \multicolumn{4}{|l|}{ Professional category } \\
\hline Professionals, managers & $-1.5(6.1)$ & $-6.4^{*}(6.3)$ & $-4.5(12.1)$ \\
\hline White-collar workers & $+.6(9.5)$ & $-.8(12.9)$ & $-5.6(12.4)$ \\
\hline Self-employed & $-1.0(8.3)$ & $-5.0(8.8)$ & $-1.2(17.2)$ \\
\hline Skilled blue-collar workers & $+3.7^{*}(14.5)$ & $+6.8^{*}(19.8)$ & $+6.7^{*}(28.7)$ \\
\hline Unskilled blue-collar workers & $+3.7(13.9)$ & $+4.3^{*}(20.6)$ & $+3.9^{*}(28.0)$ \\
\hline Retired & $-2.9(7.8)$ & $+2.6(18.8)$ & $-1.2(17.1)$ \\
\hline Nonactive & $-.7(9.3)$ & $-1.8(12.7)$ & $-5.9^{*}(13.2)$ \\
\hline \multicolumn{4}{|l|}{ Education } \\
\hline Primary & $+2.8^{*}(11.1)$ & $+6.3^{* * *}(21.2)$ & $+7.9^{* *}(23.8)$ \\
\hline Lower secondary & $-1.0(9.2)$ & $+.2(15.9)$ & $+3.4(20.2)$ \\
\hline Higher secondary & $+1.5(121)$ & $-3.1^{*}(12.0)$ & $-1.1(17.2)$ \\
\hline Higher & $3.9^{*}(53)$ & $-3.5^{* *}$ & $9.3^{* * *}(7.4)$ \\
\hline \multicolumn{4}{|l|}{ Religious involvement } \\
\hline No religious beliefs & $+7.9^{* * *}(18.3)$ & $+9.3^{* * *}(22.7)$ & $-2.2(15.1)$ \\
\hline Humanists (free thinkers) & $+5.7^{*}(14.7)$ & $+.7(12.8)$ & $-2.0(15.0)$ \\
\hline Marginal Catholic & $+.2(10.0)$ & $+2.8(17.4)$ & $+1.6(19.5)$ \\
\hline Irregular churchgoers & $-2.4(6.8)$ & $-2.5(12.9)$ & $+3.6^{*}(18.7)$ \\
\hline Regular churchgoers & $-5.1^{* *}(4.1)$ & $-9.5^{* * *}(6.9)$ & $-10.2^{* *}(6.4)$ \\
\hline \multicolumn{4}{|l|}{ Age } \\
\hline-24 & $+4.9^{*}(16.9)$ & $+2.1(15.9)$ & $+3.5(17.0)$ \\
\hline $25-34$ & $-.9(10.9)$ & $+2.0(16.4)$ & $+5.9^{*}(16.8)$ \\
\hline $35-44$ & $-.8(9.1)$ & $-3.3(12.3)$ & $-.2(17.5)$ \\
\hline $45-54$ & $-2.6(7.6)$ & $-5.0^{* * *}(10.2)$ & $-2.7(16.4)$ \\
\hline $55-64$ & $-2.11(6.0)$ & $+1.6(15.5)$ & $-.7(17.7)$ \\
\hline+65 & $+4.1^{*}(8.7)$ & $+3.9^{*}(18.6)$ & $+4.0^{*}(17.0)$ \\
\hline \multicolumn{4}{|l|}{ Health insurance fund } \\
\hline Christian & $-.1(8.5)$ & $+1.2^{*}(14.5)$ & $-2.2(15.1)$ \\
\hline Socialist & $+.2(13.1)$ & $-1.1(17.6)$ & $+2.9(22.2)$ \\
\hline Liberal & $-3.5(6.8)$ & $-9.7^{* * *}(6.8)$ & $+.4(14.8)$ \\
\hline Other & $+2.5(11.2)$ & $+.1^{* *}(16.5)$ & $+4.3(17.8)$ \\
\hline \multicolumn{4}{|l|}{ Trade Union membership } \\
\hline Christian & $-.7(9.4)$ & $+4.9^{*}(19.7)$ & $+4.5(21.4)$ \\
\hline Socialist & $+2.1(14.8)$ & $+.2(16.9)$ & $+7.8^{*}(24.7)$ \\
\hline Other & $-.0(8.5)$ & $-2.2(12.4)$ & $-7.9^{*}(7.9)$ \\
\hline None & $-.2(9.0)$ & $-1.7 .(12.9)$ & $-2.0(14.9)$ \\
\hline \multicolumn{4}{|l|}{ Active membership } \\
\hline Yes & $+.6(11.1)$ & $-2.2^{*}(11.6)$ & $-.8(13.8)$ \\
\hline No & $-.9(7.5)$ & $+1.5(16.8)$ & $+.5(19.0)$ \\
\hline$N$ (sample sizes) & 2,501 & 1,942 & 1,036 \\
\hline
\end{tabular}

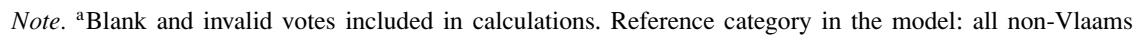
Blok voters. The weighted observed percentages are given in brackets. These percentages are weighted in the sample for gender, education, level of education, and election result. All percentages are bivariate percentages. $* p \leq .05 ;{ }^{* *} p \leq .01 ; * * * \quad p \leq .001$.

about the total effects of these background variables on the probability ratio. In Table 1, the effect parameters are expressed as deviations from the average percentage obtained by the Vlaams Blok in 1991, 1999, and 2003. The figures in Table 1 are the net effects of each predictor on the probability of a vote for the Vlaams Blok, after elimination of the effect of all other predictors in the statistical model. 
Table 2. Direct Significant $(p<.05)$ Net Effects of Attitudes on a Vote for the Vlaams Blok in the Elections to the House of Representatives in Flanders in 1991, 1999, and 2003 ${ }^{a}$

\begin{tabular}{llll}
\hline Attitudes & \multicolumn{1}{c}{$\beta(1991)$} & \multicolumn{1}{c}{$\beta(1999)$} & \multicolumn{1}{c}{$\beta(2003)$} \\
\hline Negative attitudes toward immigrants & $1.520^{* * *}(89.61)$ & $1600^{* * *}(82.41)$ & $1461^{* * *(39.60)}$ \\
Flemish nationalism & $1.115^{* * *}(12.96)$ & $1.236^{* * *}(33.52)$ & $1.328^{* * *}(28.82)$ \\
Authoritarian attitudes & $1.005(.01)$ & $1.124^{*}(3.82)$ & - \\
Severe repression of criminals & - & $1.274^{* * *}(13.60)$ & $1.043(.34)$ \\
Political inefficacy and distrust & $1.005(.01)$ & $1.154^{* * *}(9.01)$ & $1.152^{*}(4.34)$ \\
$N$ & 2,232 & 1,862 & 1,022 \\
\hline
\end{tabular}

Note. ${ }^{a}$ Multiplicative logistic regression parameters $(\beta)$ controlled for social background variables (see Table 1). Chi-square (1 $d f$ ) of maximum likelihood analysis of variance in the complete model between brackets.

${ }^{*} p \leq .05 ;{ }^{* *} p \leq .01 ; * * * p \leq .001$.

For example, an effect parameter of -3.9 in the category of the higher educated means that the mean likelihood of voting for Vlaams Blok $(9.7 \%)$ is 3.9 percentage points lower as a consequence of belonging to the category of the higher educated. Controlled for the other variables in the model, the likelihood of voting for Vlaams Blok is $5.8 \%$ in this category.

In the second step of the analysis, the attitudinal variables are included in the models. Because these are metric variables, we do not express their effects as deviations in average percentages, but as multiplicative logistic regression parameters affecting the ratio proportion, Vlaams Blok/other party. This ratio is called probability ratio or, more simply, odds. The parameters express the amount of change in the odds Vlaams Blok/other party when the value of the attitudinal variable increases with one unit standard deviation $(S D)$. Parameters with a value close to 1.0 do not have any effect on the odds; parameters significantly lower than 1.0 express a decrease in odds; and parameters significantly higher than 1.0 express an increase. The parameters of the attitudinal variables are shown in Table 2. A parameter of 1.52 for the attitudinal variable negative attitude toward immigrants means that in 1991, the odds Vlaams Blok/all other voters increases with a factor of 1.52 when the score on the attitudinal variable increases with one unit $S D$. Table 2 is the main table of this article because it is directly related to our hypotheses. The effects of the social background variables change after including the attitudes. We do not report this, however, because we are not interested in a decomposition of the direct and indirect effects of the social background variables.

\section{Results}

\section{Background Variables and the Vote for the Vlaams Blok}

Table 1 contains the results relevant for the test of the hypotheses on background variables in 1991, 1999, and 2003. Gender did not make an independent contribution and was not included in Table 1. The results in Table 1 corroborate the 
hypothesis that blue-collar workers more strongly vote for the Vlaams Blok. This is especially true for the skilled blue-collar workers. This is in line with our expectations and with the findings in, for example, France and Austria (see Pettigrew, 1998). Voting for that party is less likely among the professionals since the 1999 elections and among white-collar workers in 2003. These findings complement the findings regarding the blue-collar workers. The results are also supportive of the hypothesis on the level of education. In all three election years, a vote for Vlaams Blok is more likely among voters who received less formal training (primary education), whereas the high-skilled voters (higher education) are clearly less likely to support this party.

The results concerning religious involvement are mostly in line with our expectations too. Respondents without any religious affiliation were more likely to vote for the Vlaams Blok in 1991 and 1999. Regular churchgoers were less likely to join the electorate of the extreme right-wing party in the three election years. In past research, we explained this effect of regular churchgoing by typical characteristics of Flemish Catholicism. This Catholicism is strongly organized around such values as justice, care, and solidarity, and the Christian Democratic Party was in the core of the organization network (Billiet, 1995). The estimated positive net effect of irregular churchgoers on a vote for the Vlaams Blok in 2003 (estimated 20.67\%) seems to reject our hypothesis in 2003. This could indicate that more recently, new social categories of voters are joining the electorate of that party. It is possible that the steady growth of the electorate of the right-wing party realizes a shift in the social composition of its electorate.

The results regarding the age categories of the voters partly corroborate and partly refute our hypotheses. We note higher probabilities of voting for the Vlaams Blok among voters between 18 and 34 years of age in 1991 and 2003. The shift from the youngest age category in 1991 (mostly new voters) to the category of 2534 years of age 10 years later in 2003 could indicate that the generation born in the 1970s remains more likely to vote for the extreme right. This is in harmony with the finding that voters for the Vlaams Blok are likely to stick to their previous choice in the future (see e.g., Swyngedouw \& Billiet, 2002). Opposing our hypothesis, however, is the finding that the oldest category of voters is more likely to support the Vlaams Blok. This curvilinear relation with age seems present in all three elections. Voters in the age category of 45-54 years were least likely to vote for the extreme right in 1999. This was not predicted by our theories either.

We hypothesized that respondents not associated with the traditional pillar organizations and voters who do not actively participate in organizational life are more likely to vote for the Vlaams Blok. Our results mostly refute these hypotheses. Members of a nontraditional health insurance fund are only slightly more supportive for the Vlaams Blok in 1999, and the effect is rather modest. Trade union membership does not show the expected associations with a Vlaams Blok 
vote. Active membership in voluntary associations was only associated with a lower probability to vote Vlaams Blok in 1999.

Has the impact of the background variables changed compared to the beginning of the 1990s? The most striking finding relates to education. The effect of primary education only in 2003 has grown compared to 1991 (from +2.8 to +7.9 ). Note that also the effect of higher education grew during that period (from -3.9 to -9.3). This suggests that education became more important as a predictor of extreme right-wing voting behavior between 1991 and 2003. The proportions of both lower and higher educated in the electorate remained nearly the same during this period. The effect of professional category, and especially the category of the skilled blue-collar worker, also became more important during the same period (an increase from +3.7 in 1991 to +6.7 in 2003). Finally, the increase in effect of the regular churchgoers is also noticeable (from -5.1 in 1991 to -10.2 in 2003). This, however, does not affect substantially the grand mean of the Vlaams Blok since the marginal number of regular churchgoers in the electorate has been halved during the same period.

\section{Attitudinal Determinants of a Vlaams Blok Vote}

In a second step, attitudes are added to the background variables in the model. This allows us to examine the net effects of the attitudes on a vote for the Vlaams Blok, after controlling them for each other and for the background characteristics. The parameters of the significant attitude variables are given in Table 2. Two attitudes affect a vote for the Vlaams Blok in the three elections presented in Table 2. The most important attitude is undoubtedly a negative attitude toward immigrants. The odds Vlaams Blok/other party increases by $52 \%$ in 1991 , by $60 \%$ in 1999 , and by $46 \%$ in 2003 for an increase of one standard unit on the scale. These findings are in line with the theory of threatened economic interests. In addition, Flemish nationalism plays a role, thus corroborating the theory of symbolic interests. The odds Vlaams Blok/other party expanded by $11 \%$ in 1991 and by $33 \%$ in 2003 , with an increase of one standard unit on the scale. The two remaining theories receive far less support. Authoritarian attitudes (and a severe approach to the issue of criminality) only play a role during the election of 1999, but seem irrelevant in 1991 and 2003. Political inefficacy and distrust have a modest effect on the Vlaams Blok vote in 1999 and 2003 only.

It is rather difficult to assess the evolution of the importance of the four attitudes because of different operationalizations across the three election studies. The scale measuring negative attitudes toward immigrants is factorially invariant over time. As a consequence, the parameters of this scale are comparable, even though changes in the strength and composition of the other scales affect these parameters too. Everyday racism seems to be roughly as important in 2003 as it was in 1991. This suggests that the importance of the theory of threatened economic 
interests in explaining the Vlaams Blok vote is stable over time. The results in Table 2 also seem to suggest that the importance of Flemish nationalism (and thus of the theory of symbolic interests) and of the protest motive increased slightly over time. This conclusion is not really justified, however, because the measurements of both attitudes are not completely comparable over time. The conclusion regarding the stability of the effect of everyday racism on the Vlaams Blok vote is more valid.

\section{Conclusion and Discussion}

Combining the results of both the background characteristics and the attitudinal determinants of voting behavior allows us to address our hypotheses in a more comprehensive way. In overall terms, our analyses confirm that the choice for the Vlaams Blok expresses a content-related preference for the political program of this extreme right-wing party. This is in line with the rational choice model of voting behavior (e.g., Himmelweit et al., 1981). Our results also suggest that the issue of everyday racism plays a prominent role in explaining this voting behavior because most evidence supports the theory of threatened economic interests. All the hypotheses derived from this theory are confirmed by our analyses. The preference for the Vlaams Blok is higher among blue-collar workers and low-skilled respondents, whereas a negative attitude toward immigrants strongly determines the vote for this party, as assumed in this theory. It should be noted, however, that categories that feel economically threatened by immigrants (blue-collar workers and low-skilled individuals) also adopt a more conservative sociocultural attitude (e.g., De Witte \& Billiet, 1999). This also leads them to reject immigrants because immigrants differ in terms of customs and culture from the majority culture. As a consequence, the theory of threatened economic interests should be extended to threats related to economic and cultural issues and perhaps even to other topics such as criminality. This broadening aligns well with the notion of everyday racism, as developed elsewhere (De Witte, 1999). These results answer our core research question: everyday racism constitutes the most important attitudinal determinant of political racism in Flanders in the period between 1991 and 2003.

In addition to everyday racism, the analyses also suggest that the other three theories play a subordinate, additional role in explaining the preference for an extreme right-wing party. The theory of symbolic interests, which emphasizes nationalism as a determinant, is partly confirmed and partly refuted. In line with this theory are the results suggesting that nonchurchgoers (and especially those without religious beliefs) vote to a greater extent for the Vlaams Blok. The hypothesis that active members of a voluntary association are less likely to vote for the Vlaams Blok voters received only limited support. The prediction about the negative relationship between membership in traditional social organizations and the Vlaams Blok vote was not confirmed. Members of the socialist and Christian trade unions were 
even more likely to vote for this party during specific elections. The Flemish nationalist attitude of the respondents does play a role in predicting an extreme right-wing vote in Flanders. This finding corroborates the theory of symbolic interests.

The theory of psychological compensation is only partially corroborated by our results. Authoritarian attitudes were only relevant as voting determinants during the elections of 1999, but not in 1991 or 2003. The impact of this theory thus seems limited. The higher probability to vote Vlaams Blok among the blue-collar workers and lower educated is in line with this view. The findings concerning background characteristics can be interpreted in various ways, however, because they are also in line with the theory of threatened economic interests.

Finally, the Vlaams Blok vote also seems to reveal an undertone of apolitical protest, even though the results regarding the background characteristics are fairly ambivalent. In line with the protest hypothesis, we find a higher probability to vote the Vlaams Blok among blue-collar workers, low-skilled individuals, and nonchurchgoers. The results concerning active membership in organizational life are less convincing. The finding that the elderly are more likely to vote for the Vlaams Blok in 1991 and 1999 contradicts this hypothesis. The analysis of the attitudinal variables shows that political inefficacy and distrust play only a secondary role in determining the vote for this party in two of the three elections. This suggests that the preference for this extreme-right wing party reveals an undertone of political protest.

The conclusions discussed above all relate to the direct effects of the various attitudes on the vote for the Vlaams Blok. The multivariate analyses show that everyday racism is the main determinant of political racism. Nationalism, authoritarian, and apolitical protest all play an additional role. These three attitudes, however, also affect the Vlaams Blok voting in an indirect way because these three attitudes are also related to everyday racism. This has been shown regarding nationalism (Meloen, De Witte, \& van der Linden, 1999), authoritarianism (Meloen, 1994), and expressions of apolitical protest (Billiet \& De Witte, 1995). These three attitudes can, therefore, also be regarded as "underlying" determinants influencing the vote for an extreme right-wing party in an indirect way.

\section{References}

Adorno, T., Frenkel-Brunswik, E., Levinson, D., \& Sanford, R. (1950). The authoritarian personality. New York: Harper \& Row.

Altemeyer, B. (1998). The other “authoritarian personality.” In L. Berkowitz (Ed.), Advances in experimental social psychology (Vol. 30, pp. 47-92). Orlando, FL: Academic Press.

Billiet, J. (1995). Church involvement, ethnocentrism and voting for a radical right wing party: Diverging behavioral outcomes of equal attitudinal dispositions. Sociology of Religion, 56, 303-326.

Billiet, J., \& De Witte, H. (1995). Attitudinal disposition to vote for an extreme right-wing party-the case of "Vlaams Blok." European Journal of Political Research, 27, 181-202. 
Billiet, J., \& De Witte, H. (2001). Wie stemde in 1999 voor het Vlaams Blok en waarom? [Who voted Flemisch Blok and why?]. Tijdschrift voor Sociologie, 21, 5-36.

Billiet, J., Goffé, H., \& Maddens, B. (2007). Een Vlaams-nationale identiteit en de houding tegenover allochtonen in een longitudinaal perspectief [translation]. In M. Swyngedouw, J. Billiet, \& B. Goeminne (Eds.), De kiezer onderzocht. De verkiezingen van 2003 en 2004 in Vlaanderen (pp. 95-120). Louvain: Universitaire Pers Leuven.

Billiet, J., Swyngedouw, M., Depickere, A., \& Meersseman, E. (2001). Structurele determinanten van het stemgedrag en culturele kenmerken van de kiezerskorpsen in Vlaanderen. De verkiezingen van 1999 [Structural determinants of voting behaviour and cultural characteristics of the voters in Flanders: The elections of 1999]. Louvain: K.U. Leuven, ISPO.

De Baets, A. (1994). De figuranten van de geschiedenis. Hoe het verleden van andere culturen wordt verbeeld en in herinnering gebracht [The figurants of history. How the past of other cultures is divided and remembered]. Berchem: EPO.

De Witte, H. (1999). Everyday racism in Belgium: An overview of the research and an interpretation of its link with education. In L. Hagendoorn \& S. Nekuee (Eds.), Education and racism. A crossnational inventory of positive effects of education on ethnic tolerance (pp. 47-74). Aldershot: Ashgate.

De Witte, H., \& Billiet, J. (1999). Economic and cultural conservatism in Flanders: In search of concepts, determinants and impact on voting behavior. In H. De Witte \& P. Scheepers (Eds.), Ideology in the low countries. Trends, models and lacunae (pp. 91-120). Assen: van Gorcum.

De Witte, H., \& Klandermans, B. (2000). Political racism in Flanders and the Netherlands: Explaining differences in the electoral success of extreme-right wing parties. Journal of Ethnic and Migration Studies, 26, 699-717.

Fraeys, W. (2004). Les élections régionales et européennes du 13 juin 2004: Analyse des résultats [The regional and European elections of June 13 2004: Analysis of results]. Res Publica, 46, $357-376$.

Himmelweit, H., Humphreys, P., Jaeger, M., \& Katz, M. (1981). How voters decide. A longitudinal study of political attitudes and voting extending over fifteen years. London: Academic Press.

Lubbers, M. (2001). Exclusionist electorates. Extreme right-wing voting in Western Europe. Doctoral thesis, UNIVERSITY NAME, Nijmegen.

Lubbers, M., \& Scheepers, P. (2000). Individual and contextual characteristics of the German extreme right-wing vote in the 1990s. A test of complementary theories. European Journal of Political Research, 38, 63-94.

Meloen, J. (1994). A critical analysis of forty years of authoritarianism research. In R. Farnen (Ed.), Nationalism, ethnicity and identity: Cross-national and comparative perspectives (pp. 127165). New York: Transaction Books.

Meloen, J., De Witte, H., \& Van Der Linden, G. (1999). Authoritarianism and voting for a racist party in Belgian Flanders. Politics, groups and the individual. International Journal of Political Psychology and Political Socialization, 8, 21-40.

Näswall, K., \& De Witte, H. (2003). Who feels insecure in Europe? Predicting job insecurity from background variables. Economic and Industrial Democracy, 24, 189-215.

Pettigrew, T. F. (1998). Reactions towards the new minorities of Western Europe. Annual Review of Sociology, 24, 77-103.

Swyngedouw, M., \& Billiet, J., Eds. (2002). De kiezer heeft zijn redenen. 13 juni 1999 en de politieke opvattingen van Vlamingen [The voter has his reasons. June 131999 and the political opinions of the Flamish]. Louvain: Acco.

Van Der Brug, W., Fennema, M., \& Tillie, J. (2000). Anti-immigrant parties in Europe: Ideological or protest vote? European Journal of Political Research, 37, 77-102.

JAAK BILLIET, PhD in the Social Sciences, is Professor in Social Methodology at the Katholieke Universiteit Leuven, Belgium. He is head of the Centre for Sociological Research (CESO) and a member of the central coordination team of the European Social Survey (EC FP6). His main research interest in methodology 
deals with validity assessment, interviewer and response effects, and the modeling of measurement error in social surveys. His substantial research covers longitudinal and comparative research in the domains of ethnocentrism, political attitudes, and religious orientations. He also plays a central role in the implementation of the fourth wave of the European Value Study in 2008.

HANS DE WITTE, PhD in Psychology, is Professor in Work Psychology at the Department of Psychology of the Katholieke Universiteit Leuven, Belgium. His research interests include psychological consequences of work and unemployment (including job insecurity, temporary employment, and downsizing), attitudes toward work, the impact of job characteristics on social and political attitudes, racism, and right-wing extremism. 